\title{
IMAGINANDO A IMAGEM NO TURISMO: UMA VIAGEM DE IDA E VOLTA
}

\author{
Agustín Santana-Talavera
}

\begin{abstract}
RESUMO
O papel que a imagem tem no desenvolvimento do turismo e, em especial, enquanto elemento de diferenciação de um destino turístico, é hoje uma realidade amplamente reconhecida. Isto reflete-se na literatura, onde se procura identificar as variáveis que motivam a compra ou incentivam o processo de decisão. Contudo, a referência a processos de retroalimentação ou a mecanismos de controlo da imagem, assim como da criação da mesma, é pouco usual. Neste artigo pretende-se expor um modelo de compreensão destes processos.
\end{abstract}

\section{Patavras-chave}

Imagem; destino turístico; sistema turístico; turismo; turista-consumidor

\section{IMAGINING THE IMAGE IN TOURISM: A ROUND TRIP}

\begin{abstract}
Currently, the role of the image in the development of tourism and, especially, as an element of differentiation of a destination area is widely recognized. This is reflected in the literature, which seeks to identify the variables that motivate the purchase or incentivize the decision process. However, the reference to feedback processes or control mechanisms of the image, as well as its creation, is unusual. This article aims to present a model of understanding these processes.
\end{abstract}

\section{KEYWORDS}

Image; tourism; tourist-consumer; tourist destination; tourist system

\section{INTRODUÇÃ̄o ${ }^{1}$}

A competitividade, o dinamismo e a inovação são atributos próprios de todo sistema turístico. É raro não encontrar referências a estas características em quase qualquer artigo acadêmico, declaração institucional, projeto de intervenção ou demanda por recursos que envolva a atividade turística. E a cultura-consumo tipo Kleenex, de uso e descarte, é a principal responsável por isto.

O mercado exige renovação constante na forma ou no conteúdo dos produtos e destinos, ainda que muitos sejam apresentados como tradicionais, históricos ou "o de

\footnotetext{
' Uma versão anterior deste artigo foi publicada em Santana-Talavera, 2015.
} 
sempre". Alguns destes elementos renovados são óbvios e seu consumidor é partícipe ou cúmplice venturoso, sempre que se realize o devido condicionamento estético ao seu uso e sejam oferecidas as comodidades requeridas pelo momento turístico.

Este é o contexto da "imagem do destino" que - rançosa ou imbuída de virtualidades e tecnologias - é criada e apresentada à plêiade de compradores e consumidores em um jogo paradoxal de continuidade e renovação, de familiaridade e contraste, de tradição (remetida a um passado reconstruído à la carte) e modernidade, com uma apresentação sem fissuras, como um todo somente divisível se o destinatário assim o deseja ou pode fazê-lo por conta própria.

Nos destinos - estas entidades conformadas como obras de engenharia coletiva com a finalidade exclusiva de exploração econômica de atributos reais ou imaginários (supostas paisagens, infraestrutura de exploração, comunicações, etc. agrupados por seu caráter territorial e de produto-serviço oferecido como experiência integrada (Bigne, Font \& Andreu, 2000) -, diante do caos aparente confluem atores dentro de uma ordem e de uma definição operacionais com interesses definidos.

Agrupando-os sem considerá-los em absoluto como homogêneos (Nash, 1996; Santana Talavera, 2003b), tem-se: (a) a população residente; (b) os turistas e (c) os trabalhadores estrangeiros (geralmente temporários), aos que haveria de acrescentar (d) grupos humanos assentados em áreas não necessariamente próximas ao destino turístico. Vários grupos e muitas culturas, subculturas e variações culturais, todos sujeitos a possíveis mudanças derivadas das relações estabelecidas entre si e com os produtos ofertados e consumidos no processo turístico, além de outros não imediatamente suscetíveis às mudanças ocasionadas pelo turismo.

Talvez um dos elementos mais característicos desta singular população dos destinos seja a falta de homogeneidade. Os imaginários e seus referentes devem ser escoIhidos e diferenciados para uma clientela mais ou menos definida (nível econômico e educacional, faixa etária, procedência sociocultural, demandas), embora obstritos por uma série de elementos físicos disponíveis - atributos, recursos, produtos - e por uma população empresarial e laboral que também deve se adaptar ou se mostrar suficientemente flexível à sazonalidade, às mudanças de grupos de consumidores, às circunstâncias laborais, etc., além de uma população residente que deve se ajustar às mudanças que se sucedem no seu entorno. Um processo em constante evolução, sujeito a mudanças e ajustes em busca da sobrevivência turística, como Butler (1980) descreveu o ciclo de vida dos destinos, atualizado por Tom Baum (1998).

Atualmente, quando se reconhece não só o turismo como uma das atividades econômicas legais mais importantes do planeta como também o seu incremento às economias nacionais e domésticas, tem-se um amplo consenso da importância que a imagem tem como núcleo e motor desta atividade. Uma boa amostra disto é que só outro item, o dos impactos do turismo, compete com a imagem como tema de interesse pelas investigações desenvolvidas na literatura especializada. Excelentes trabalhos como os de Gallarza, Gil Saura e Garcia Calderon (2002) ou Frias, Rodríguez e Castañeda (2007) realizam uma revisão exaustiva, e Baloglu e McCleary (1999), em um texto que marcou 
várias investigações posteriores, repassam os principais trabalhos que se desenvolveram sobre temas como o impacto da visita, a familiaridade da imagem, a relação entre a localização geográfica do turista e da imagem, medida da imagem do destino, seus componentes e fatores que a influenciam, diferença entre a imagem do turista e a imagem projetada pelo destino, variações na imagem segundo o propósito da viagem, relação entre variáveis sociodemográficas e imagens do destino, etc.

Os autores diferenciam duas aproximações entre os estudos de estrutura estática e os de estrutura dinâmica, segundo verifiquem, respectivamente, as relações entre a imagem e o comportamento do turista, ou o interesse na estrutura e formação da imagem do destino turístico. Sendo esta última aproximação a menos frequente na literatura especializada, pretende-se aqui contribuir para sua discussão a partir de um ponto de vista transdisciplinar.

\section{A gLOBALIDADE DA IMAGEM: DEFINIÇÕES, DESENHOS E CONSTRUÇÕES}

Desde a década de 1990 (Hum \& Crompton, 1990; Gallarza et al., 2002; Gartner, 1993) que se tende a considerar a imagem turística como uma construção conceitual complexa e subjetiva (Bigne, Sanchez \& Sanchez, 2001), em que se fundem a razão e a emoção do consumidor com avaliações que comparam o conhecimento e a experiência sobre o destino. Isto é, um conjunto de representações mentais a respeito dos atributos físicos do destino turístico como um todo (componente cognitivo), combinados com as avaliações e sentimentos que desperta (componente afetivo) (Baloglu \& Brinberg, 1997).

Este tipo de concepção se integra plenamente em um modelo cambiante da imagem centrada tanto nos atributos físicos da área do destino como na percepção por parte do consumidor-turista, que é quem, em última análise, forma um fotograma único carregado de sensibilidades, emoções e avaliações tanto cognitivas como afetivas (St. Martin Gutierrez, Rodriguez Del Bosque \& Vazquez Casilles, 2006). A imagem se torna, portanto, individualizada (segundo a definição de Hunt, 1975) e marcada pelo papel de atividade-passividade exercido por todo turista no desenvolvimento de sua viagem (Mercille, 2005), circunscrito ao consumo e associado ao marketing.

Tomada desta forma, a análise da imagem deixaria de lado outros atores implicados no processo de desenho, formação e transmissão que vão confluir no imaginário do destino. Isto é, o perfil que os grupos envolvidos na origem projetam de sua própria ambiência na construção da identidade local, que o identificará ou por sua unicidade ou por comparação subjetiva com outros destinos. A imagem no sistema turístico é praticamente o item que configura o destino e determina em grande medida a satisfação e a recordação turística, sobretudo, por comparação na experiência de ser turista em um destino. Além disso, os efeitos socioculturais sobre as populações locais de imagens alheias a si mesmas são sentidos a médio prazo, modificando padrões e traços de condutas, valores e relações, reconstruindo as identidades locais (Franklin \& Crang, 2001).

Assim, parece necessário contemplar a imagem de maneira global, a partir de um enfoque sistêmico processual, o que leva a diferenciar claramente processo de 
concepção, desenho e atividade dos materiais que conformam a imagem construída para venda dos processos de percepção e interiorização (criação e comparação individual). Trata-se de abrir os esquemas e modelos de investigação a uma dupla vertente de processos retroalimentados e interconectados que metodologicamente permitam um estudo passo a passo, com indicadores válidos em cada um deles.

\begin{tabular}{|c|c|c|c|}
\hline & DESTINO & TURISTA-CONSUMIDOR (Primeira Visita) & OBJETIVO \\
\hline \multicolumn{2}{|c|}{ Auto-imagem: residente (1) } & $\underline{\text { PRÉ-COMPRA }} \rightarrow \begin{array}{l}\text { Processo de formação da } \\
\text { imagem }\end{array}$ & \multirow{3}{*}{ Atração } \\
\hline \multirow{4}{*}{ 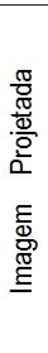 } & $\begin{array}{l}\text { Imagem montada } \\
\text { para venda (2) }\end{array}$ & - Global (indireta, difusa e compósita) & \\
\hline & Imagem promovida (3) & $\rightarrow$ Especifica (turistica) & \\
\hline & \multirow{2}{*}{$\begin{array}{l}\text { Imagem recriada } \\
\text { pelos tour-operadores (4) }\end{array}$} & โ Processo de eleição do destino $\downarrow$ & \multirow{2}{*}{ Venda } \\
\hline & & $\underline{\text { COMPRA }} \rightarrow$ Imagem vendida (5) & \\
\hline \multicolumn{3}{|c|}{$\underline{\text { CONSUMO }}$ - Imagem percebida $(6)$} & Satisfação \\
\hline \multicolumn{3}{|c|}{ Imagem compartilhada - recordação (7) } & Fidelização \\
\hline
\end{tabular}

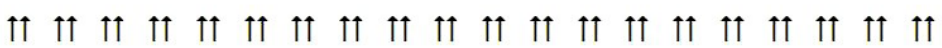

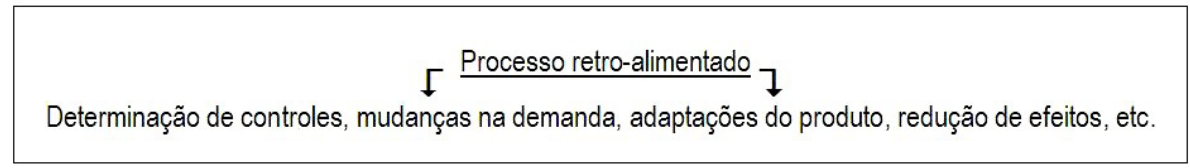

Figura 1: Modelo geral das imagens no turismo (criação, consumo, recriação)

Fonte: Baseado em Santana Talavera e Pinto, 2008

Costuma-se supor que os atributos sobre os quais uma imagem de destino se assenta são em parte físicos (entorno, infraestrutura, clima) e em parte intangíveis (a cultura, a amabilidade, a familiaridade, o bem fazer, a identidade). Desde fins da década de 1980 assistimos à aparição em cascata de muitos "novos turismos", propiciados em seu conjunto pelas novas condições e exigências do mercado, isto é, competitividade, flexibilidade e segmentação. Estes novos produtos se apresentam como "uma forma diferente de fazer turismo" e a máxima é produzir para o cliente uma experiência satisfatória, a experiência do autêntico na natureza, na cultura, nas pessoas ou uma combinação disso tudo.

Sobre uma plêiade de denominações comerciais se destacam o ecoturismo, o turismo étnico, turismo rural e turismo cultural, este último de aplicação mais ampla. Seu desenvolvimento é efetivado, preferivelmente, em áreas não congestionadas em termos populacionais (paragens desabitadas ou com muito baixo nível de ocupação humana, entornos rurais não urbanos ou pequenos povoados concentrados), mas podem incluir 
tours monumentais-arquitetônicos ou vinculados a museus ou se apresentar como subconjuntos de ofertas em novos turismos de massa. É neste contexto de novas buscas que as populações residentes, antes atores passivos, passam a formar parte substancial da imagem construída para a venda e se tornam importantes para a autoimagem (aquela percebida pelos residentes de si mesmos) e da área em que convivem.

Enquanto que a autoimagem foi raramente incorporada às análises turísticas, a temática das atitudes frente à imagem vem sendo um objeto sobejamente estudado (Getz, 1994; Lawson, Young \& Cossens, 1998; Lindberg \& Johnson, 1997; Ryan \& Montgomery, 1994; Smith \& Krannich, 1998), considerando que a atitude pode afetar em grande medida a imagem percebida.

A incorporação da autoimagem pode agregar veracidade às campanhas publicitárias, identificando atributos e evitando performances desnecessárias, mas também estabelece limites (espaciais, qualitativos, quantitativos ou temporais) ao desenvolvimento ou à exploração turística das áreas. Entende-se que a autoimagem pode não ser única, posto que dependerá dos diferentes grupos socioculturais e socioeconômicos que dão forma à população local, além dos níveis de integração da população estrangeira no dado contexto.

Em uma situação ideal grande parte da autoimagem deverá ser refletida, pelo menos, na imagem construída para venda e, finalmente, na imagem vendida, mas isto raramente ocorre. As representações ideais que cada um tenha de si mesmo e do meio são dificilmente encaixadas pela demanda de um lugar mítico - o paraíso em suas múltiplas e cambiantes versões - que coexista nos lugares geradores de turistas. Por este motivo não é estranho encontrar imagens construídas e promovidas sobre recursos virtuais, efêmeros ou demasiadamente adornados, como tampouco o é a inclusão como atrezzo de elementos tão variáveis como o clima ou os eventos sociais (Santana-Talavera, 2003b).

Em tais circunstâncias, pela eficiência econômica e organizativa para a população residente e pelas exigências da lógica de mercado, a autoimagem, o cotidiano, são concebidos como uma cópia cuja qualidade se mede em termos de sua adaptação para o consumo. Converte-se em um argumento para sua venda como imagem construída, mostrando as facilidades de acesso, a inocuidade e o exotismo, no modelo clássico, ou o perigo, o risco, o desamparo e a aventura, nas mais refinadas formas de desenho nas novas experiências turísticas mais ou menos carregadas de sensacionalismo segundo nos desloquemos da "autenticidade" à "realidade" turisticamente comercializada. Motivações, expectativas e atividades multidimensionais que se reflitam na complexidade e intangibilidade da imagem (Villa, 2001).

A imagem construída para venda costuma vir marcada pelos interesses das instituições e do empresariado, assim como, em menor medida, pelos residentes. É usual encontrar-se com três estratégias mais ou menos limitadas: i) uma política conjunta e participativa de todos ou parte dos envolvidos no desenho da imagem na seleção de atributos, produtos e seus referentes físicos e emocionais sobre a identidade do destino; ii) uma seleção mais ou menos interessada realizada em torno dos produtos e das atividades disponíveis na área, agrupados por blocos temáticos ou subáreas territoriais; iii) 
um conglomerado de iniciativas mais ou menos articuladas, geralmente exógamas, que tendem supervalorizar tal ou tal atributo do destino em função da sua demanda.

As políticas turísticas baseadas na sustentabilidade dos destinos turísticos (as que atendem às necessidades dos turistas atuais sem comprometer a possibilidade do usufruto dos recursos pelas gerações futuras ${ }^{2}$ ) recomendam fortemente a primeira das opções, tanto que, ao ancorar a imagem do destino à sua autoimagem, não reduzem-se os efeitos negativos da atividade turística, como também provê à área de visitação ferramentas dinâmicas de resposta às mudanças do mercado sem graves alterações na sua estrutura social e econômica.

Esta estratégia evita em grande medida que os bens e espaços cotidianos sejam transformados em produtos de representação, tratando de ajustar o respectivo atrativo ou recurso (ou decisão relativa aos atributos locais) sem deslegitima-los culturalmente. De fato, não foram poucas as ocasiões em que o meio ambiente, a própria cultura ou uma seleção desvirtuada deles, foram objetivados, despersonalizados e retirados do contexto a fim de se obter um produto extemporâneo apresentado como autêntico, para remeter a uma ideia de experiência única e inesquecível para seu consumidor (Markwell, 2001) e, ao mesmo tempo, replicável e estandardizado.

A segunda e mais frequente das estratégias de elaboração da imagem construída costuma vir determinada por especialistas e aplicada a destinos em uma fase intermediária de seu ciclo de vida (Butler, 1980). Diz respeito não tanto a grandes inovações, mas sim a alterações e incrementos agregados a campanhas promocionais anteriores. Em termos gerais, trata-se de manter vantagens competitivas modificando as atribuições de recursos e produtos, combinando atividades e introduzindo infraestruturas. Como indica Schouten (1995), uma boa interpretação está baseada em conexões realizadas com ideias e experiências que sejam já familiares. E no aumento da curiosidade dos visitantes. Esta forma de diversificação da imagem construída pode ser facilmente reconduzida até às estratégias participativas quando se aplica a pequenos destinos, mas se encontra com sérios problemas operativos e conflito de interesses quando se trata de áreas amplas e consolidadas.

Por último, a terceira estratégia radica na adaptação das "realidades" a seus destinatários (residentes e turistas), podendo oferecer uma apropriação estética e uma experiência emocional com um lapso de tempo extremamente curto. Este modo, combinado ou não com a participação, pode ser contemplado especialmente nas novas áreas turísticas surgidas na remodelação do sistema nos anos 1990. No pior dos casos, quando a exogamia da imagem construída prevaleceu e os mercados não responderam os impactos socioeconômicos foram realmente importantes. E isso sem a presença de turistas propriamente ditos (frustração na geração de expectativa e compromisso de capitais), rompendo assim o esquema conceitual da imagem e do sistema turístico. A vantagem desse tipo de reinterpretação da imagem construída do destino é que permite a entrada de múltiplos produtos individualizados com ou sem cobertura da marca ou identidade do destino.

\footnotetext{
${ }^{2}$ Ver World Comission of Environment and Development, 1987.
} 
Supondo qualquer um dos casos anteriores, as ideias que compõem tal desenho se materializam em diversas campanhas de promoção, formando-se o que se denomina imagem promovida. Um desenho marcado para comercialização, em grande medida, pela demanda e por elementos publicitários sobre os atributos mais ou menos presentes na área e pela imagem construída.

Têm importante papel neste processo as instituições regionais e locais, e em muito menor medida o empresariado. Através da análise de recentes campanhas promocionais é observável como o "líder criador" (pessoa ou grupo) das organizações-instituições turísticas imprime sua marca, tratando de consolidar (muitas vezes por períodos legislativos) projetos de destino que expressem determinado nível de qualidade (condicionado pela concorrência e pela identidade do destino), honestidade (não enganar o cliente), preparação (profissionalismo nos serviços e produtos oferecidos) e capacidade de resposta aos valores e desejos de um conjunto ou segmento de mercado destinatário (tendência a um turismo a la carte). O cumprimento de objetivos (número, frequência e tipo de turistas) e a maturidade organizativa (persistência) determinarão em grande medida a solidez do projeto e, dentro das limitações e incertezas próprias do sistema turístico, sua durabilidade efetiva (tempo exitoso no mercado).

Ainda que raramente ocorram mudanças drásticas, a passagem da imagem construída à imagem promovida obriga pequenos ajustes para se adaptar às variações na demanda, à competição de outros destinos e às necessidades concretas de comercialização diante de segmentos de mercado (turistas potenciais). Esta forma que a imagem é figurada é simultaneamente enormemente flexível e definidora do destino ante o consumidor, isto é, ao mesmo tempo em que permite um conjunto de alterações figurativas ao combinar produtos e/ou potencializar novos recursos, limita o rol de possiblidades da característica interior.

A imagem promovida, com um importante componente físico, tangível, que se reflete em panfletos, folhetos, brochuras, cartazes e outras formas de material publicitário, é o que se pode encontrar junto a outros adereços nas feiras turísticas dirigidas, sobretudo, aos tour-operadores e varejistas ou agente de viagem, ainda que em algumas ocasiões seja possível que se realize grandes campanhas publicitárias para chegar ao grande público.

A importância geral deste componente da imagem global reside em sua posição como motivador consciente e inconsciente que anima o indivíduo a se somar à corrente turística, mediante estímulos simbólicos que evocam estados anímicos determinados (relaxamento, aventura, descobrimento, diversão, etc.). Em um âmbito mais concreto, seu objetivo é contribuir para consolidar a decisão da compra sobre o destino e tipo de turismo determinado.

Neste ponto, é atribuível à imagem promovida tanto o papel de geradora como de reforçadora de estereótipos sobre o destino (de caráter grupal) (Echtner \& Ritchie, 1991; Gallarza, et al., 2002) como de promotora de expectativas (de caráter individual) (Litvin \& MacLaurin, 2001; Litvin \& Ng Sok Ling, 2001) sobre a área, os produtos promovidos e as emoções causadas pelo seu consumo. Contudo, há que se entender que a imagem 
dos destinos turísticos é incremental, isto é, não é diretamente substituta de uma outra campanha promocional, porque áreas com imagens negativas ou degradadas terão que empenhar muito mais esforço, recursos e tempo que outros com uma imagem positiva forte para ser incluídas no pool de destinos elegíveis nos processos de tomada de decisão (Fakeye \& Crompton, 1992; Frías, et al., 2008).

Sem embargo, a escolha do destino é condicionada também por outros fatores, fundamentalmente econômicos (custos, descontos e possibilidades de pagamento ou endividamento), temporais (sazonalidade), temporais (coincidência com o período de férias escolares e laborais) e incidentais (presença de menores ou idosos, clima, segurança, tempo de viagem, etc.). Ainda que seja cada vez mais frequente que as áreas de destino se promovam a si mesmas (se proponham como elegíveis), não significa que elas próprias se encarreguem dos processos de venda dos seus produtos (tipo centrais de reservas), uma vez que o topo do mercado da intermediação turística é ocupado por alguns grupos de operadores multinacionais (agentes atacadistas) (até 55\% das viagens de férias contratadas no RU em 2001, segundo Parra López, Melchior Navarro \& Ramos Domínguez, 2003).

Em sua geração e adaptação à demanda e melhor composição de negócio (Martín de la Rosa, 2003), os tour-operadores podem combinar tanto o produto de um mesmo destino como produtos de áreas diferenciadas, e inclusive vários destinos com todos os seus produtos. Ou mesmo criar produtos (sobretudo de serviços) totalmente novos que se inserirão em um ou alguns destinos específicos. Entende-se assim uma imagem recriada que pode ser projetada não homogeneamente para o mercado pelos diferentes operadores, em paralelo à imagem promovida introduzida pelas instituições, organismos e, em menor medida, empresas locais (Andreu, Bigné \& Cooper, 2000, referem-se a imagem projetada, que no esquema que propomos se subdivide metodologicamente em imagem promovida e imagem recriada).

Neste processo, o tour-operador aproxima a viagem ao consumidor, sobretudo pela primeira vez, intermediando a compra de um produto específico (conjunto de bens serviços). Este chega ao cliente através das agências de viagem (agentes varejistas), que podem modificar substancialmente as imagens (tanto de forma positiva como negativa) e as impressões geradas sobre o destino. $O$ agente de viagem não costuma conhecer pessoalmente nem o destino, nem os produtos nem a imagem promovida (muito menos a imagem construída para venda). E desse modo, em última análise, ele próprio interpreta e oferece ao possível consumidor um destino-produto baseado quase que exclusivamente no material promocional do tour-operador (imagem recriada) e na sua própria experiência/habilidade como vendedor.

$\mathrm{Na}$ prática, a informação acrescentada pelos agentes de viagem introduz novamente algumas variações não pouco importantes na imagem, conformando a imagem vendida. Ambas as imagens, recriada e vendida (correspondentes aos canais de distribuição como sujeitos ativos), são as que consolidam expectativas sobre o cliente-turista potencial, que adquire o gozo temporalmente limitado de alguns produtos constituídos por bens, serviços, atividades, território, clima, paisagem, cultura, etc. Ou, o que é o 
mesmo, paga por uma apropriação temporal e acordada de uma porção do destino e as experiências neles replicáveis.

Usualmente as imagens projetadas (promovida, recriada e vendida) se definem por uma série de variáveis ou códigos (Ronai, 1976, referindo-se à paisagem). Podendo operativamente ser simplificadas e decompostas em quatro categorias de elementos: a. funcional (mobilidade, infraestruturas, possibilidades de relação ou atividade); b. pitoresco e grandioso (cenários peculiares com qualidades plásticas, monumentalidade e paisagismo); c. emotivo (evocação de sentimentos); d. único (atributos tangíveis ou intangíveis de uma área e somente dela).

Em teoria a disposição do destino-espetáculo, onde tudo que acontece pode ser construído e regulado como atrativo, conclui com sua apresentação à população consumidora com uma uniformidade de estilo, léxico e diversidade temática (segundo os grupos de destinatários) e ícones representativos padrões. Dependendo dos produtos e atividades turísticas específicas (ficam à margem o reality tourism, o voluntourism e formas semelhantes), dá-se uma valorização fundamentalmente estética da área ocultando as possíveis contradições tanto entre o espaço e o resto da sociedade anfitriã, como entre os grupos sociais que a compõem, oferecendo uma aparente harmonia.

\section{A GLOBALIDADE DA IMAGEM: INDIVIDUALIDADE E RECORDAÇÃo}

O sujeito do olhar, o turista-ator, apreende a imagem como parte dos seus processos cotidianos e como um objeto da cultura que visita (normalmente oculta sob o véu da atividade turística), em um exercício de codificação, interpretação e valorização comparativa a partir do seu modo de vida e cultura de origem, mediado pelo sistema turístico.

A espacialidade e a temporalidade do cotidiano são limitadas no destino quando não suspendidas a priori, reforçando o caráter imanente (essencial) do que foi criado para o deleite turístico e é este o lugar onde a imagem se completa. Portanto, a imagem percebida se mostra como um conjunto total (Assael, 1984) de crenças, ideias e impressões do lugar visitado (Crompton, 1979), justapostas aos estereótipos e expectativas acumuladas antes da visita.

Neste sentido, a imagem individualizada como representação mental passa por um longo processo de formação que se pode iniciar inclusive antes que o cliente potencial deflagre a motivação para viajar. Isso pode suceder indiretamente desde que os indivíduos tenham acesso a informações globais que vão sendo tematizadas segundo interesses pessoais, de grupo, sociais, políticos, meio-ambientais, etc., criando-se estados de opinião e conhecimentos específicos, pré-configurando imagens e estereótipos simplificados (a imagem orgânica proposta por Gunn, 1972, e desenvolvida por Fakeye \& Crompton, 1991), segundo suas características sociodemográficas (gênero, idade, escolaridade, renda, principalmente). É certo que este tipo de informação indireta costuma ser vaga e imprecisa, mas predispõe os indivíduos à recepção de discursos mais elaborados turisticamente (imagem induzida segundo os mesmos autores ou imagem projetada, como fora nomeado no presente texto) e, consequentemente, há uma maior 
probabilidade de aparição de motivações (Castaño, Crego \& Moreno, 2006) e seleção de um tipo de destino concreto.

Baloglu e McCleary (1999) estabelecem que o transcurso da imagem passa pelo conhecimento direto ou indireto dos atributos objetivos de um lugar sobre o qual se geram emoções, diferenciando entre os fatores estímulo (fontes de informação segundo quantidade e tipo, experiência prévia e distribuição) e fatores pessoais (psicológicos valores, motivações e personalidade - e sociais - características sociodemográficas). $\mathrm{Na}$ aplicação empírica deste modelo, Beerli e Martín (2004) desenvolvem uma categorização dos fatores estímulo, distinguindo entre (i) fontes secundárias, isto é, informação percebida antes da estadia, subdividida em orgânica, induzida e autónoma, e (ii) fontes primárias, formadas durante a estadia, determinando a importante influência das fontes de informação induzida (canais de distribuição) e autônoma (guias de viagem) como fatores determinantes da eleição do destino e da imagem global percebida.

Ainda que as características individuais do turista condicionem em maior ou menor medida a apreensão da imagem do destino e sua avaliação, os estereótipos difundidos pelos media (Bardón Fernández, 1991) a desvirtuam e tratam de forçar o indivíduo a adaptar sua própria observação/participação à imagem que resulta mais conveniente ao negócio turístico (mais rentável e menos custosa). E algo parecido, mas de consequências mais duradouras acontece às populações de destino.

Tudo parece indicar que a experiência como turista e a procedência sociocultural dos clientes (Santana-Talavera, 1997), e não diretamente sua nacionalidade (Beerli \& Martin, 2004), influenciarão tanto nos aspectos cognitivos como afetivos da imagem percebida. Ambos aspectos assentam sua relevância na capacidade e conhecimento para comparação de imagens, atributos, serviços e experiências do destino com as vividas anteriormente em suas viagens ou no cotidiano, além das expectativas prévias da viagem. Neste sentido, as impressões ou emoções sempre são subjetivas (e dificilmente quantificáveis) e se encontram separadas, ainda que relacionadas, dos elementos tangíveis do destino turístico. Sobre estes quase especificamente se realizam atribuições que são confrontadas valorativamente, colocando em evidência não só a semelhança ou diferença assinalada, senão tendendo, além disto, à generalização por analogia.

Assim, entrevistas realizadas (Cruz Modino, 2004, 2007; Pinto, 2007; Rodríguez Darias, 2007) demonstram que, ainda que o turista no destino esteja continuamente em um exercício de contraste (inclusive com o mais familiar), qualquer elemento não esperado ou anômalo será incluído no balanço afetivo e avaliado positiva ou negativamente.

Diante da semelhança em facetas, qualidades ou relações com uma situação anteriormente experimentada, o indivíduo desenvolverá emotividades e formas de comportamento como se respondesse àquela situação inicial, afetando a imagem percebida no momento presente. Ao fundamentar-se em impressões, este processo constitui um dos motivos pelos quais a imagem percebida do destino turístico pode distanciar-se (Gartner, 1993) daquilo que a população residente e os agentes permanentes do destino podem considerar, dito com toda cautela, como uma imagem objetiva ou real.

A confrontação da imagem percebida por parte do turista com o jogo de expectativas não preditivas e estereótipos tomados pelas imagens orgânica e projetada, deriva 
de um juízo valorativo (cognitivo-afetivo) de sua experiência (Santana-Talavera, 2003a). É o que se conhece como satisfação no turismo (Bigne, et al., 2001; Echtner \& Ritchie, 1991; Westbrook, 1987;). Sendo o objetivo final do turismo a maximização de benefícios - negá-lo é parte da utopia -, a principal preocupação dos destinos é obter um alto nível de satisfação de sua clientela e, se possível, fidelizar tanto estes turistas quanto os seus próximos. Mas, como assinalado, são muitos os fatores que podem distorcer a imagem percebida (Teye, Sönmez \& Sirakaya, 2002) e com isso afetar os níveis de satisfação (entendidos numa gradação bipolar não-satisfação/satisfação contínua) e insatisfação (de igual forma não-satisfação/insatisfação) (Westbrook, 1987). Por isso se faz necessário determinar não apenas tais níveis de maneira global sem decompô-los, ao menos, nas mesmas variáveis e fatores empregados para análise da imagem e a geração de expectativas.

A experiência do turista há de se entender desta maneira, como um conjunto de vivências que se inicia nas motivações conscientes, se desenvolvem na viagem, estadia no destino e regresso à sua normalidade, concluindo com a configuração da lembrança, sua comunicação e a comparação própria com seus semelhantes (imagem compartilhada).

\section{Conclusão}

Algumas pessoas se referem aos dias de hoje como propícios para voltar a imaginar um passado neorromântico ou de homens bons que admiravam os selvagens - à distância, claro - e ainda obtinham prestígio por fazê-lo. Tempos caracterizados (ao menos no ocidente, que contém os países que emitem o maior número de turistas) pelo tempo livre reconhecido como direito e pelos altos níveis de consumo e de capacidade de endividamento individual e do núcleo doméstico jamais vista. Estes são os condicionantes que nos inserem na aldeia global, aquela que impele a olhar cotidianamente para além das pequenas fronteiras e assim, por uma ameaça de perda imediata, a focar nos localismos, a se manifestar no contexto de hibridação cultural, isto é, na conjugação de ideias, de essências e relações materiais, de significados e estruturas que se fundem em uníssono.

O Éden, historicamente presente e quase universal, antigamente sonhado e contado como vergel, camaleônico Olimpo cultural, adaptante e adaptável segundo os rigores e rubores de cada sociedade e cada momento histórico, encontra-se hoje invadido, repleto de redes para repousar, gentes que se percebem como atores e câmaras fotográficas que demostram e guardam o caminho por ali imortalizado numa banal instantânea. Nem a guerra, nem a fome, nem a ânsia reprodutiva haviam movido a humanidade como o faz a atividade turística. E nem a melhor literatura romântica sonhou com tal variedade de devaneios, de estereótipos mais ou menos filtrados que fizeram dos outros parte do paraíso particular, quase um para cada turista e para cada um dos que desejariam sê-lo.

Principalmente é imputável à atividade turística esta rede de expectativas. Mas os efeitos, os impactos, não só a ela, exclusivamente. É quase impossível distinguir o 
quanto se deve ao sistema turístico e sua incessante geração de imagens sobre produtos e destinos, de outras influências tais como a televisão ou o cinema, com programações e sequencias sem uma intencionalidade declarada na motivação da viagem; quanto ao efeito demonstração que nos impulsiona a conjugar nossos interesses com os demais, a sentir aquilo que outros disseram que sentiram; quanto à iniciativa e criatividade individuais. Mas os estudos de caso parecem indicar que, contudo, a resultante destas e outras variáveis é uma imagem que se infiltra na cultura ocidental, que se assume como cotidiana e nos move a convertermo-nos em passageiros, em hóspedes temporários do sistema, cada um agrupado segundo expectativas, motivações, esperanças e desejos de experimentar nosso paraíso particular.

Essa imagem, quase culturalmente apreendida como processo, gera lembranças não vividas, espaços desejados e para o desejo promessas de encontros com outros, os iguais em menor grau, os diferentes, sobretudo, ocultando as desigualdades em princípio e realçando-as quando o produto assim o requer.

Longe do bom selvagem submetido aos domínios do Império, os atores do sistema turístico se tornam parte ativa na manipulação dos signos, produzindo, reproduzindo e consumindo, segundo o papel representado e ao modo de simulacros atemporais, as formas culturais comercializáveis. Os consumidores do produto turístico, cúmplices no consumo da autenticidade, legitimam-se com o incremento de seu papel ativo na criação de significados. É preciso verificar quem oferece estes significados ou ao menos as pautas básicas para inferi-los ou gerar "inovadoramente" estas novas versões de significados em uso já para outras áreas. A originalidade não é precisamente o que prima nos destinos turísticos, sejam estes culturais ou de massa ou de qualquer outro tipo, o que induz a crer que realmente existem os arquitetos da hibridação.

Apresentou-se neste texto uma forma distinta de contemplar a formação da imagem turística global, a fim de orientar investigações e contribuir para a discussão sobre ferramentas teóricas e metodológicas, com o convencimento de que é possível estabelecer um enquadramento de entendimento, de crítica e de discussão a respeito do sistema turístico e dos processos que em nele se desenvolvem.

\section{Tradução(castelhano-português): Roque Pinto e Rodrigo Ortega}

\section{REFERÊNCIAS}

Andreu, L., Bigné, J. E. \& Cooper, C. (2000). Projected and perceived image of Spain as a tourist destination for british travellers. Journal of Travel Q Tourism Marketing, 9(4), 47-67.

Assael, H. (1984). Consumer behavior and marketing action. Boston: Kent Publishing.

Baloglu, S. \& Brinberg, D. (1997). Affective images of tourism destination. Journal of Travel Research, 35(4), 11-15.

Baloglu, S. (2001). Image variations of Turkey by familiarity index: informational and experiential dimensions. Tourism Management, 22, 127-133. 
Baloglu, S. \& Mangaloglu, M. (2001). Tourism destination images of Turkey, Egypt, Greece, and Italy as perceived by US-based tour operators and travel agents. Tourism Management, 22, 1-9.

Baloglu, S. \& McCleary, K. W. (1999). A model of destination image formation. Annals of Tourism Research, $26(4), 868-897$.

Bardón Fernández, E. (1991). El paisagem na oferta turística recreativa. Estudios Turísticos, 112, 27-54.

Baum, T. (1998). Taking the exit route: extending the tourist area life cycle model. Current Issues in Tourism, $1(2), 167-175$.

Beerli, A. \& Martin, J. D. (2004). Factors influencing destination image. Annals of Tourism Research, 31(3), 657-681.

Bigné, J. E., Font, X. \& Andreu, L. (2000). Marketing de destinos turísticos: análise y estratégias de desenvolvimento. Madrid: ESIC Editorial.

Bigne, J. E., Sanchez, M. I. \& Sanchez, J. (2001). Tourism imagen, evaluation variables and after purchase behaviour: inter-relationship. Tourism Management, 22(6), 607-616.

Butler, R.W. (1980). The concept of a tourism area cycle of evolution: implications for management resources. Canadian Geographer, 24(1), 5-12.

Castaño, J. M., Crego, A. \& Moreno, A. (2006). Factores psicosociales y formación de imágenes en el turismo urbano: un estudio de caso sobre Madrid. PASOS. Revista de Turismo y Patrimonio Cultural, 4(3), 287-299.

Crompton, J. L. (1979). Motivations for pleasure vacation. Annals of Tourism Research, 6(4), 408-424.

Cruz Modino, R. de la (2004). Patrimonio Natural y Reservas Marinas. PASOS. Revista de Turismo y Patrimonio Cultural, 2(2), 179-192.

Cruz Modino, R. de la (2007). Proteger el mar, conservar las culturas: turismo y pesca en la Reserva Marina Punta de La Restinga - mar de Las Calmas (El Hierro, Islas Canarias) y en el Área Natural Protegida de las Islas Medas (Girona, Cataluña), Investigación en curso. La Laguna, Tenerife: Universidad de La Laguna.

Echtner, C. M. \& Ritchie, B W. (1991). The meaning and measurement of destination image. The Journal of Tourism Studies, 2(2), 2-12.

Echtner, C. M. \& Ritchie, B. W. (1993). The measurement of destination image: an empirical assessment. Journal of Travel Research, 31(4), 3-13.

Fakeye, P. C. \& Crompton, J. L. (1991). Image differences between prospective, first-time, and repeat visitors to the Lower Rio Grande Valley. Journal of Travel Research, 30(2), 10-16.

Fakeye, P. C. \& Crompton, J. L. (1992). Importance of socialization to repeat visitation. Annals of Tourism Research, 19(2), 364-367.

Franklin, A. \& Crang, M. (2001). The trouble with tourism and travel theory? Tourist Studies, 1(1), 5-22.

Frías, D. M., Rodríguez, M. A. \& Castañera, J. A. (2008). Internet vs. travel agencies on pre-visit destination image formation: An information processing view. Tourism Management, 29(1), 163-179

Gallarza, M. G., Gil Saura, I. \& Calderón García, H. (2002). Destination image. Towards a conceptual framework. Annals of Tourism Research, 29(1), 56-78. 
Gartner, W. C. (1993). Image formation process. Journal of Travel and Tourism Marketing, 2(2/3), $191-215$.

Getz, D. (1994). Residents' attitudes towards tourism: a longitudinal study in Spey Valley, Scotland. Tourism Management, 15(4), 247-258.

Gunn, C. A. (1972). Vacationscape. Designing tourist regions. Washington, DC: Taylos and Francis/University of Texas.

Hunt, John D. (1975). Image as a factor in tourism development. Journal of Travel Research, 13(3), 1-7.

Kozlowski, J. (1986), Threshold approach in urban, regional and environmental planning: theory and practice. St. Lucia: University of Quennsland Press.

Lawson, R. W., Williams, J., Young, T. \& Cossens, J. (1998). A comparison of residents' attitudes towards tourism in 10 New Zealand destinations. Tourism Management, 19(3), 247-256.

Lindberg, K. \& Johnson, R. L. (1997). Modeling resident attitudes toward tourism. Annals of Tourism Research, $24(2), 402-424$.

Litvin, S. W. \& MacLaurin, D. J. (2001). Consumer attitude and behavior. Annals of Tourism Research, 28(3), 821-823.

Litvin, S. W. \& Ng Sok Ling, S. (2001). The destination attribute management model: an empirical application to Bintan, Indonesia. Tourism Management, 22(5), 481-492.

Markwell, K. (2001). An intimate rendezvous with nature? Mediating the tourist-nature experience at three tourist sites in Borneo. Tourist Studies, 1(1), 39-58.

Martín de la Rosa, B. (2003). La imagen turística de las regiones insulares: las islas como paraísos. Cuadernos de Turismo, 11, 127-137.

Mercille, J. (2005). Media effects on image: the case of Tibet. Annals of Tourism Research, 32(4), 1039-1055.

Nash, D. (1996). Anthropology of tourism. Oxford: Pergamon.

Parra López, E., Melchior Navarro, M. \& Ramos Domínguez, Á. (2003). Análisis e impacto de los touroperadores y las agencias de viaje en el transporte turístico: nuevas tendencias en Canarias.

PASOS. Revista de Turismo y Patrimonio Cultural, 1(2), 217-229.

Pinto da Silva Santos, R. (2007). Padrones actitudinales de gestores en el turismo en Ilhéus, Brasil. Investigación en curso. La Laguna, Tenerife: Universidad de La Laguna.

Rodríguez Darias, A. J. (2007). Turismo en áreas protegidas. El caso de los parques rurales de Tenerife (Islas Canarias, España). Investigación en curso. La Laguna, Tenerife: Universidad de La Laguna.

Ronai, M. (1976). Paysages. Hérodote, 1, 125-159.

Ryan, Ch. \& Montgomery, D. (1994). The attitudes of Bakewell residents to tourism and issues in community responsive tourism. Tourism Management, 15(5), 358-369.

San Martín Gutiérrez, H., Rodríguez del Bosque Rodríguez, I. \& Vázquez Casilles, R. (2006). Análisis de la imagen en turismo mediante técnicas estructuradas y no estructuradas: implicaciones competitivas para los destinos turísticos. Revista Asturiana de Economía, RAE, 35, 69-91.

Santana-Talavera, A. (1997). Antropología y turismo. ¿Nuevas hordas, viejas culturas? Barcelona: Ariel. 
Santana-Talavera, A. (2003a). Jugant a ser amfitrions: trobades i impactes en el sistema turístic. Revista d'etnologia de Catalunya, 22, 46-53.

Santana-Talavera, A. (2003b). Mirando culturas: la antropología del turismo. En Á. Rubio Gil (Ed.), Sociología del turismo (pp. 103-125). Barcelona: Ariel.

Santana-Talavera, A. (2015). Imaginando la imagen en turismo: un viaje de ida y vuelta. Revista de Antropología Experimental, 15, 37-53.

Santana-Talavera, A. \& Pinto, R. (2008). Tourism in the consumer society: anthropologic subsidies to the static subsystem figuration. Journal of Hospitality and Tourism, 6, 87-110.

Smith, M. D. \& Krannich, R. S. (1998). Tourism dependence and resident attitudes. Annals of Tourism Research, 25(4), 783-802.

Teye, V., Sönmez, S. \& Sirakaya, E. (2002). Residents' attitudes toward tourism development. Annals of Tourism Research, 29(3), 668-688.

Um, S. \& Crompton, J. L. (1990). Attitude determinants in tourism destination choice. Annals of Tourism Research, 17(3), 432-448.

Villa, A. D. (2001). El turismo cultural o la mercantilización de la cultura. Comunicação apresnetada no Congreso Virtual de Turismo 2001. Retirado de http://www.equiponaya.com.ar/turismo_cultural/ congreso/ponencias/aurora_daniel_villa.htm

Westbrook, R.A. (1987). Product/consumption-based afective responses and postpurchase processes. Journal of Marketing Research, 24(3), 258-270.

\section{NOTA BIOGRÁFICA}

Agustín Santana-Talavera, é doutorado em Antropologia Social, professor de Universidade da Universidade de La Laguna (Tenerife), Diretor do Instituto Universitário de Pesquisa Social e Turismo da mesma universidade e Diretor- Adjunto da Secretaria de Turismo CajaCanarias-ASHOTEL-ULL. As suas linhas de pesquisa inscrevem-se na Antropologia do Turismo, verificadas, desde 1983, em sete livros (como autor único ou editor) e na produção de 55 artigos em periódicos nacionais e internacionais (dos quais 15 em JCR e / ou SCOPUS), bem como colaborações com 57 capítulos em diversos livros científicos. Em 14/01/2018, seu índice h é 15 e i10 23. É o fundador e diretor do PASOS. Revista Internacional de Turismo e Patrimônio, revista eletrônica (www.pasosonline.org - ISSN 1695-7121) internacional e multidisciplinar.

Email: asantana@ull.es

Morada: Universidad de La Laguna, Pabellón de Gobierno, C/ Molinos de Agua s/n. | San Cristóbal de La Laguna, Santa Cruz de Tenerife - Espanha (38200)

* Submetido: 28-02-2018

* Aceite: 09-05-2018 